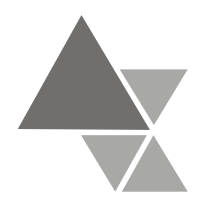

\title{
Alterações nas Estratégias de Subsistência: $O$ Caso dos Índios Brasileiros Xavantes $^{1}$
}

\author{
Rafael José Navas da Silva ${ }^{2}$; Maria Elisa de Paula Eduardo Garavello ${ }^{3}$
}

\section{Resumo}

O objetivo deste trabalho foi analisar as transformações ocorridas na alimentação da comunidade indígena xavante, da aldeia Wedérã, no Estado de Mato Grosso, Brasil, com a introdução da agricultura mecanizada. Foi utilizado o enfoque qualitativo, com técnicas de entrevista e observação participante. Verificou-se que, com a introdução da mecanização na produção agrícola e o processo de sedentarização, o arroz tornou-se base da alimentação, substituindo outros alimentos tradicionalmente consumidos, obtidos principalmente através da coleta. A utilização da caça ainda permanece, entretanto, com maior impacto ambiental. Outras alterações na dieta são a compra de alimentos industrializados e a composição das refeições do Programa Nacional de Alimentação Escolar - PNAE, popularmente conhecido como merenda escolar. Tais transformações podem estar associadas à causa de 56,3\% de prevalência de anemia entre a população da aldeia, constatada em 2006. Há esforços para alterar esse quadro, mas, mudanças no modo de vida e organização social dos indivíduos e nas relações destes com a natureza, podem estar comprometendo a sua segurança alimentar e nutricional de modo irreversível.

Palavras-chave: estratégias de subsistência; Jê; Hábito alimentar; Sociedade de caçadores-coletores; Segurança alimentar.

\section{Changes in Subsistence Strategies: The Case of the Xavante Brazilian Indians}

\begin{abstract}
The work aims to study the changes in food habit among the Xavante's (a brazilian Indians tribe) living in Wede'rã village, part of Pimentel Barbosa Reserve in the Mato Grasso State, in Brazil. Through personal interviews and participant observations we could see that food production mechanization, instead fruits and vegetable gathering, have increased the white rice consumption and have caused the abandon of nomadic practices, bringing bad consequences for health. Hunting is still practiced, but also is having ecological negative effects. Together with the increasing use of industrialized food, as in the school lunches, these changes in food consumption are associated with higher (56.3\% in 2006) anemia rates. There are some efforts in order to revert present situation, but changes in their life style, in their social organization, in their social organization and in their relationship with their environment is an irreversible threat to their food and nutritional security.
\end{abstract}

Key-words: strategies of subsistence; Jê; Food habit; Hunting and gathering societies; food security.

\footnotetext{
${ }^{1}$ Artigo baseado na Dissertação intitulada "Seis décadas de contato: transformações na subsistência xavante", apresentada ao Programa de Pós-graduação em Ecologia Aplicada - ESALQ/CENA/USP em 2008.

${ }^{2}$ Engenheiro agrônomo, Mestre em Ecologia Aplicada - Escola Superior de Agricultura “Luiz de Queiroz" - ESALQ/USP

- Programa de Pós-graduação Ecologia Aplicada.

${ }^{3}$ Professora Dr $^{\mathrm{a}}$ do Departamento de Economia, Administração e Sociologia - ESALQ/USP, Avenida Pádua Dias, 11, 13418-900, Piracicaba-SP, (19)3429-4225, E-mail: mepegara@esalq.usp.br
} 


\section{Introdução}

\section{A história xavante}

Os primeiros relatos históricos sobre os xavantes datam de 1762. Naquela época eles habitavam a bacia do Tocantins, juntamente com os xerentes. Ambos, xavantes e xerentes formam o ramo Acuen dos povos da família linguística Jê do Brasil Central. Historicamente este povo foi forçado a migrações constantes, fugindo do contato com o não-índio, sempre em busca de novos territórios onde pudesse se refugiar. Entre 1820-1856 cruzaram o rio Araguaia tentando escapar de exploradores e garimpeiros e, nesta época houve a cisão do grupo entre xavantes e xerentes. Apenas este último grupo aceitou a aproximação do não-índio. Até 1890, os xavantes ocupavam uma área entre o Rio Araguaia e o Rio das Mortes, vivendo em isolamento. A pressão de frentes de expansão da sociedade nacional levou-os por volta de 1890 para o sul e sudoeste de Mato Grosso, atravessando o Rio das Mortes e estabelecendo-se próximos à Serra do Roncador ${ }^{[1]}$. O contato pacífico com o nãoíndio, mais especificamente com a FUNAI, ocorreu a partir de 1946, decorrente de intensos esforços governamentais, no sentido de abrir a região a projetos de colonização. A partir deste momento, ocorreram surtos epidêmicos, redução dos territórios e o processo de sedentarização, instaurando assim, a dependência da agricultura para alimentação.

Antes do contato permanente, a economia da sociedade xavante era baseada na caça e coleta, com excursões de seus habitantes pelo território durante vários meses, garantindo a sua subsistência. Estas excursões eram realizadas por grupos familiares, com posterior agregação dos mesmos em grandes aldeias, na época do plantio e colheita dos produtos agrícolas.

De acordo com Silva ${ }^{[2]}$, mesmo após o contato pacífico, os xavantes da Terra Indígena Pimentel Barbosa, continuaram com estilo de vida caracterizado pela mobilidade espacial, com excursões de caça e coleta pelo território até meados de 1980. Sua subsistência tinha como base as atividades de caça, a coleta de vegetais, a agricultura e a pesca, sendo as duas últimas consideradas de importância secundária, pelo pouco tempo que permaneciam na aldeia ${ }^{[1]}$. Estas diferentes atividades eram condicionadas pela estação do ano e sua importância relativa variava sazonalmente, garantindo uma alimentação equilibrada e completa ${ }^{[1]}$.

A caça foi descrita por MayburyLewis ${ }^{[1]}$ como atividade masculina e não se destinava apenas à alimentação, fazendo parte da cultura como um todo. A agricultura era praticada por ambos os sexos e os produtos desta atividade eram milho, feijão, abóbora e carás, que são plantas resistentes e não exigiam cuidados intensos. Devido aos seus constantes deslocamentos em seu território, os xavantes dedicavam a essa atividade no máximo um mês ao ano e mesmo neste período realizavam expedições de caça e coleta. A coleta constituía-se uma atividade feminina, sendo realizada pelas mulheres de um mesmo grupo familiar e também junto com outras mulheres da aldeia, representando uma das poucas oportunidades de 
relacionamento social para elas, fora da casa [1].

Os produtos das colheitas agrícolas tinham maior importância nas celebrações, do que como fonte essencial de sobrevivência; nestas ocasiões o tempo dos indígenas era dedicado às cerimônias, não se dedicando à caça e à coleta ${ }^{[1]}$. Giaccaria e Heide [3] ressaltaram que, com os produtos da agricultura, a comunidade dedicava-se nas épocas de colheita, à confecção de armas e renovavam a união do grupo por meio das cerimônias. Além dos produtos para alimentação, plantavam algodão, usado na confecção de ornamentos e urucum utilizado para pintura corporal nas cerimônias.

\section{Maybury-Lewis ${ }^{[1]}$ e Giaccaria e} Heide ${ }^{[3]}$ descreveram que as roças eram feitas através de um sistema denominado de roça-detoco ou coivara. Tal sistema consistia na queima de uma porção da vegetação nativa, com posterior limpeza da área que seria utilizada para a agricultura, disponibilizando nutrientes para as plantas.

É relevante ressaltar que nessa época, o Serviço de Proteção dos Índios (S.P.I.) ${ }^{4}$ incentivou esses grupos a adotarem a agricultura. Para o órgão, os mesmos possuíam um vasto território, que economicamente estava sendo pouco utilizado devido à mobilidade espacial que praticavam. Para o S.P.I., essa mesma área poderia sustentar um número bem maior de agricultores, principalmente em uma região que em poucas décadas seria aberta à colonização, com nova demarcação do território xavante. Ao

${ }^{4}$ S.P.I. foi criado em 1910 e substituído pela FUNAI em 1967. incorporar a agricultura como fonte importante de obtenção de alimentos, os xavantes poderiam se adaptar aos poucos à nova realidade que os esperava - a redução de seu território. Outra vantagem para o S.P.I. seria a maior facilidade na administração dos indígenas ${ }^{[1]}$.

Atualmente, a população xavante praticamente totaliza 13.000 pessoas, ocupando mais de 70 aldeias nas seis áreas que constituem seus territórios ${ }^{[4]}$, nas regiões da Serra do Roncador e dos vales do rio das Mortes, Culuene, Couto de Magalhães, Batovi e Garças, no leste matogrossense ${ }^{[2]}$. Seus territórios apresentam predominância de vegetação denominada cerrado.

\section{Os projetos desenvolvidos}

Desde o contato pacífico com o nãoíndio, alterações nos padrões de subsistência ocorreram principalmente pelo desenvolvimento de projetos, que a seu modo, provocaram impactos nesta população.

Nas décadas de 70 e 80 a FUNAI implementou um projeto de cultivo mecanizado de arroz nas aldeias da região Central do Brasil, visando à solução dos problemas advindos da redução dos territórios indígenas, agravados pelo desmatamento das áreas do entorno, e pela ocupação de suas terras $^{5}$. A idéia era que o excedente de produção seria destinado à comercialização ${ }^{[1]}$. Este projeto perdurou até a década de 80 , provocando alterações nos padrões de

\footnotetext{
5 A T.I. Pimentel Barbosa foi homologada apenas em 1986, havendo muitos conflitos entre índios e fazendeiros do entorno, devido à ocupação de suas terras e redução do território. Ainda hoje se observam no território áreas de ocupação de fazendas da década de 80 , com presença de currais e construções.
} 
subsistência das populações indígenas desta região, principalmente pela substituição dos produtos como o milho, pelo arroz, levando à perda de sementes tradicionais.

Recentemente, com o agravamento dos problemas de alimentação nas aldeias de Pimentel Barbosa, houve sugestão por parte dos xavantes, no sentido de aumentar a Terra Indígena para viabilizar a produção e o acesso a alimentos tradicionais. Na tentativa de evitar essa solução e "considerando que este aumento não supriria a necessidade de alimentos por estas comunidades" Associação Cana Rica, formada pelos proprietários do entorno, propôs a realização de um novo projeto de cultivo mecanizado de arroz. A duração deste projeto foi prevista para os anos de 2003 a 2009, tendo apoio da FUNAI e da Prefeitura Municipal de Canarana/MT. A área de cultivo deste projeto totalizou 90 hectares, dividida entre as seis aldeias existentes nesta T.I. A área de plantio da aldeia Wede'rã foi de seis hectares, com colheita na safra 2005-2006 de 280 sacos (60 $\mathrm{kg}$ ) de arroz. O sistema de produção foi convencional, utilizando tratores e grade aradora. Utilizou-se tratamento das sementes com inseticida e adubação química. Segundo informações obtidas em 2007, junto à técnica do Projeto, o mesmo foi extinto, devido aos altos custos dos insumos utilizados no cultivo.

Com tais projetos, o arroz passou a ser base da alimentação xavante, fato que permanece até os dias atuais.

É importante observar, que detectando este problema, ONGs têm desenvolvido

6 Informação baseada em entrevista com a técnica responsável pelo projeto da Associação Cana Rica. projetos paralelos, visando atenuar as consequiências da estratégia adotada.

Já entre 1992 e 1998, foi desenvolvido o projeto Jaburu, que consistia em um plano de manejo de caça e resultou em um levantamento cartográfico da reserva e na abertura de duas estradas, facilitando o acesso aos recursos naturais ${ }^{[5]}$.

Em 2005, também com relação à caça, a Associação Aliança dos Povos do Roncador, iniciou o Projeto Ühu em Wede'rã, visando à preservação da queixada e do cerrado, através do monitoramento por radio telemetria, de dois grupos da espécie pelo território, estudando seus locais de uso. Este projeto está em andamento na aldeia.

A ONG Nossa Tribo, com apoio da UNESCO realizou o projeto Nutrição Infantil para os xavantes entre os anos de 2005 e 2007, diagnosticando anemia em 56,3\% da população da aldeia Wedérã ${ }^{[6]}$. Tentando reverter esse quadro, houve o plantio na aldeia de três espécies nativas do cerrado - pequi, baru e jatobá, escolhidas pela comunidade, com o objetivo de diversificar a alimentação. $\mathrm{O}$ projeto cedeu à comunidade $20 \mathrm{~kg}$ de sementes de milho e $40 \mathrm{~kg}$ de sementes de feijão para plantio nas roças e também foram realizadas oficinas com as mulheres para confecção de pães e bolos utilizando produtos do cerrado, como o jatobá.

Os projetos referidos trouxeram transformações na produção de alimentos e nos hábitos alimentares dos xavantes, interferindo em seu modo de vida e na sua cultura. 
De acordo com Gugelmin e Santos ${ }^{[7]}$ o perfil de saúde-doença dos povos indígenas no Brasil é pouco conhecido, o que decorre da escassez de investigações e da falta de registro de informações de morbimortalidade. Também são escassos os dados relativos à situação nutricional. Este aspecto merece maior atenção, em virtude de o estado nutricional ser influenciado, em larga medida, por dinâmicas de transformação econômicas, sociais e culturais, assim como, por alterações nas estratégias de subsistência, consumo de alimentos e padrão de atividade física. Estas alterações são comuns no cotidiano de grupos indígenas em processo de interação com a sociedade nacional envolvente.

Em pesquisa realizada entre os xavantes, Vieira Filho ${ }^{[8]}$ aponta para uma dieta baseada no arroz e no aumento do consumo de produtos industrializados, como pães, biscoitos, açúcar e óleo. Entre os índios Suruí as mudanças alimentares, resultantes da dependência de produtos industrializados, com predominância de arroz, frituras e doces e pouca presença de carnes e frutas, têm provocado alterações na saúde da população, com elevada taxa de anemia, principalmente em crianças ${ }^{[9]}$.

O presente trabalho teve como objetivo analisar as transformações ocorridas a partir da introdução da agricultura mecanizada para produção de alimentos na aldeia xavante Wedérã, localizada na Terra Indígena Pimentel Barbosa/MT. Buscou também compreender as relações existentes entre a cultura xavante e seus modos de obtenção de alimentos, estudando como a adoção da mecanização nas práticas agrícolas levou às transformações nos aspectos sócio-culturais.
Assume-se que ao não serem considerados esses aspectos na realização das atividades de subsistência, tais transformações levaram também a problemas de saúde na população.

\section{Metodologia}

A Terra Indígena Pimentel Barbosa (14\% $41^{\prime}$ S e $\left.52^{\circ} 20^{\prime} \mathrm{W}\right)$, homologada em 1986 , possui área de 328.966 hectares e localiza-se nos municípios de Canarana e Ribeirão Cascalheira, no Estado de Mato Grosso. A população atual é de aproximadamente 1.700 pessoas, distribuídas em seis aldeias ${ }^{[10]}$. Entre estas, a Wedérã, criada em 1997, foi o local deste estudo. Conta com população atual de 57 pessoas, distribuídas em sete casas, sendo que apenas três indígenas falam fluentemente português.

Essa aldeia fica distante aproximadamente $15 \mathrm{~km}$ das aldeias Pimentel Barbosa e Etenhitipá e $110 \mathrm{~km}$ do município de Canarana/MT. Alguns membros da comunidade, normalmente os homens, vão para a cidade, numa freqüência semanal ou quinzenal.

Foram realizadas três viagens a campo para coleta de dados, entre 2006 e 2008. Utilizou-se enfoque qualitativo, com técnicas de observação participante, em que o pesquisador vivencia a rotina e integra as atividades dos pesquisados; entrevistas parcialmente estruturadas, em que alguns tópicos são fixados e outros redefinidos conforme o andamento da entrevista; entrevistas não estruturadas coletivas, em que há um diálogo livre entre pesquisador e informantes; desenhos ${ }^{[11]}$ e recordatório $\mathbf{2 4}$ horas. 
As entrevistas na aldeia foram realizadas com 12 homens e 10 mulheres, correspondendo aos integrantes adultos das sete casas existentes. Em todas as entrevistas houve a participação de um dos integrantes que falava português, o qual realizava as traduções.

$\mathrm{Na}$ cidade, as entrevistas realizadas foram na Prefeitura do Município de Canarana/MT, para obter informações referentes aos itens que compõem a merenda escolar e com a técnica responsável pelo projeto de cultivo de arroz da Associação Cana Rica, que é desenvolvido nas aldeias da T.I. Pimentel Barbosa.

\section{Resultados e Discussão}

Dentre as fontes de alimentos na comunidade, pode ser observado que permanecem algumas tradicionais, ainda que modificadas; outras estão sendo reduzidas e novas estão surgindo. Os resultados apresentados a seguir, são uma tentativa de mostrar o estágio de cada uma delas e sua importância na dieta xavante.

\section{A caça}

A caça é uma atividade exclusivamente masculina e é a principal fonte de proteína na dieta da comunidade. É praticada em locais próximos à aldeia e principalmente pelos jovens; também pode ser coletiva, quando os homens vão para locais mais distantes, locomovendo-se de carro ${ }^{7}$. Há

7 O veículo existente na aldeia é uma caminhonete, adquirida através da renda obtida com a elaboração de um $\mathrm{CD}$ com músicas xavantes. $\mathrm{O}$ mesmo pertence à Associação Aliança dos Povos do Roncador. Apenas três homens na aldeia conduzem o veículo, sendo normalmente utilizado para viagens às cidades próximas à aldeia e nas atividades de caça e coleta. uma terceira modalidade, que ocorre em ocasiões especiais, como casamentos, pela necessidade de obtenção de grande quantidade de carne. Os homens se dividem em grupos e fazem uma linha circular de fogo, para acuar os animais. Segundo o relato dos mais idosos, quando não havia delimitação do território, este tipo de caçada era realizada na estação seca, todos os anos, por ocasião do aparecimento de uma estrela e queimando locais diferentes. Atualmente, como observado, não existe época específica para ser realizada, pela escassez de animais no entorno das aldeias, causando ainda maior impacto à biodiversidade. A comunidade de Wede'rã reconhece que o fogo está sendo usado de maneira inadequada e há um trabalho de conscientização sobre este aspecto.

Para Stearman ${ }^{[12]}$ os fatores relacionados às mudanças na caça em comunidades são $o$ fim da mobilidade espacial, o crescimento da população, a participação no mercado, as mudanças tecnológicas e a redução do território. Entre os xavantes, destacamos dentre estes fatores, o fim da mobilidade espacial e a delimitação do território, diretamente relacionados à fixação das aldeias, com maior pressão de caça nas áreas mais próximas a estas, fato contornado com o uso do carro conforme referido. Outro fator a ser considerado é a introdução de armas de fogo, principalmente entre os mais jovens, em substituição às bordunas e arco e flecha, facilitando a obtenção de caça. Para Setz ${ }^{[13]}$ isto pode representar apenas redução no esforço de caça e nas horas dedicadas à atividade.

Diversas espécies animais foram identificadas no período de realização deste 
trabalho: queixada, tamanduá, veado campeiro, cervo, caititu, anta, jabuti, seriema, paca e cutia. O queixada é um animal de grande interesse nas caçadas, pois por andar normalmente em grupos de 15 a 30, permite aos indígenas a possibilidade de obter grande quantidade de carne. Mesmo assim, o número de animais mortos em cada caçada não é superior a quatro. A anta também é muito apreciada na alimentação, mas conforme declararam é um animal difícil de ser obtido.

Quando um animal é morto, há divisão da carne entre os caçadores, feita por quem o matou ou por alguém designado por ele. Tal pessoa distribui as partes conforme seu juízo ou consulta aos demais caçadores sobre a parte que preferem. A caça de queixada mostra a habilidade do caçador: os homens comparam o feito de cada um, evidenciando as qualidades individuais.

Para os xavantes, a caça também se relaciona à vida espiritual. Acreditam que através do consumo de carne de caça, irão receber mensagens dos espíritos através dos sonhos e que não sonharão se não comerem este alimento. São estes sonhos que irão orientá-los para o futuro.

\section{A coleta}

Durante o trabalho de campo, constatou-se o conhecimento pela população da aldeia Wedérã sobre diversas espécies vegetais de uso na alimentação. Tal conhecimento, entretanto, não é garantia de uso na alimentação. Pôde ser verificado que atualmente a coleta não tem a mesma importância que possuía como base alimentar no passado. As mulheres não mais a realizam com freqüência. As jovens não conhecem tantas espécies de plantas do cerrado, sua localização e época de produção. Apenas em uma casa houve o relato desta prática rotineiramente, realizada pelas mulheres deste grupo familiar. Já as demais a realizam apenas quando não há outra fonte de alimento, como o arroz, conforme informaram as mulheres na entrevista realizada em cada casa (em quatro casas houve este relato).

Vale referir que no cerrado, ambiente característico em que vivem os xavantes, há diferentes tipos de vegetação, que contribuem com diferentes espécies vegetais na alimentação, sendo frutos e tubérculos os principais.

As mulheres saem caminhando pelo cerrado com cestos, nas primeiras horas do dia, coletando os frutos encontrados. Quando vão para a roça, o que é esporádico, aproveitam para coletar frutos, como o buriti, além de frutos de palmeiras nativas do cerrado, presentes nas roças-de-toco.

Quando é época de frutificação de determinadas espécies, como pequi e baru, os membros da aldeia vão de carro até os locais conhecidos para realizarem a coleta destes, pois são produtos apreciados na dieta e as plantas produzem grande quantidade de frutos.

\section{Agricultura}

$$
\text { A introdução da agricultura }
$$
mecanizada promoveu inicialmente a perda de sementes tradicionais como milho. $\mathrm{O}$ arroz passou a ser base da alimentação e por ser produzido em grandes quantidades, atendia à necessidade de todo o ano, reduzindo desta forma, os demais cultivos. A substituição de alimentos tradicionais entre indígenas também 
foi observada por Leite ${ }^{[14]}$ entre os wari, em que o milho foi substituído pela mandioca. Entre os bororos, outro grupo Jê, os autores Pinto e Garavello ${ }^{[15]}$ descreveram que, com a influência da FUNAI e de missionários, o arroz substituiu o milho em importância na alimentação e em área cultivada, provocando a perda de variedades tradicionais e no quase abandono do Kuiadá Páru, ritual relacionado ao milho.

É importante considerar que entre os xavantes, mesmo com a introdução da mecanização, manteve-se a agricultura tradicional ainda que de forma reduzida e novas espécies foram adotadas a partir do contato com o não índio.

Pôde ser observado que a agricultura é praticada de modo diferenciado, com relação aos locais e aos modos de produção: ocorre em roças comunitárias (buru), onde toda comunidade participa do trabalho, desde a derrubada da mata, limpeza, plantio e colheita; pode ser em roças familiares (buru wauen), em que apenas o grupo doméstico realiza o trabalho; e nos quintais (rimãnana rómhurë), áreas no entorno das casas, também pertencentes ao grupo doméstico, cujo uso teve início após a sedentarização. As espécies cultivadas estão listadas nas Tabelas 1 e 2 e referem-se aos itens relatados e/ou observados, não estando relacionados à abundância relativa.

Entretanto, mesmo com maior diversidade de espécies cultivadas, o equilíbrio alimentar não é alcançado, pelo fato da agricultura ser sazonal, ou seja, praticada apenas na estação das chuvas (nos meses de outubro a março), não havendo diversidade de alimentos ao longo de todo ano, como seria possível, através dos produtos da coleta.

As atividades são realizadas por homens e mulheres: os homens derrubam a vegetação e ambos fazem as covas, o plantio e a colheita. As roças coletivas normalmente ficam distantes da aldeia e os membros da comunidade vão juntos de carro para a área escolhida, pois é uma distância considerada longe para os mais jovens, em geral de idade entre 15 e 30 anos. Esta distância é variável em função do local escolhido para o preparo das roças, em torno de 10 a $15 \mathrm{~km}$.

É importante salientar que, em 2006, não houve plantio em roça coletiva, reduzindose o plantio aos quintais, principalmente pela produção mecanizada de arroz, do Projeto da Associação Cana Rica. Posteriormente, com a suspensão do Projeto, em 2007, verificou-se a retomada do plantio em roça coletiva, com produtos tradicionais da alimentação xavante, havendo aumento no número de sementes tradicionais de milho, devido a trocas entre familiares. Neste momento, houve o envolvimento das mulheres de todas as casas, na seleção de sementes e no plantio; esta é uma atividade social praticada por elas, assim como é a caça para os homens. Outra consequiência observada da suspensão do projeto de agricultura mecanizada foi $\mathrm{o}$ aumento na prática de coleta entre as mulheres, principalmente quando estas foram para a roça, aproveitando para coletar frutos próximos ao local. Isso mostra a inter-relação existente entre as diferentes atividades para subsistência do grupo.

Desse modo, vale ressaltar que enquanto perdurou o cultivo de arroz 
mecanizado, houve uma diminuição do uso das demais formas de obtenção de alimentos. Nessa mesma época (2006), foi diagnosticada taxa de $56,3 \%$ de anemia entre a população da aldeia, constatado através do projeto da $\mathrm{ONG}$ Nossa Tribo, conforme referido anteriormente. Observando-se uma retomada das atividades de roça e coleta tradicionais, a partir da suspensão do projeto de cultivo de arroz, é de se esperar uma redução desse problema.

O trabalho em grupo, realizado por vários membros da aldeia, torna fundamental para manutenção da comunidade, pois o grupo familiar pode abrigar muitos dependentes improdutivos. Se a produção doméstica predominar nesses casos, pode acarretar em escassez de alimentos. Outro impacto deste tipo de produção seria a falta de excedentes, levando à redução nas trocas entre famílias ${ }^{[16]}$.

Leite ${ }^{[17]}$ ressalta a importância do trabalho coletivo no conjunto de relações interpessoais. $\mathrm{O}$ autor defende que no trabalho em grupo, a aprendizagem se dá em menor tempo, tendo a tendência a menor número de erros nas tomadas de decisões.

Tabela 1. Espécies cultivadas nas roças na aldeia Wede rã entre 1998 e 2007.

\begin{tabular}{lll}
\hline Roças coletivas em pousio & Roças familiares & Roça coletiva atual \\
\hline Abacaxi & Abacaxi & Abóbora \\
Abóbora & Abóbora & Arroz \\
Algodão xavante & Araticum & Batata-doce \\
Arroz & Arroz & Banana \\
Banana & Algodão & Cará nativo \\
Batata-doce & Banana & Cana-de-açúcar \\
Cana-de-açúcar & Batata-doce & Feijão xavante \\
Cará nativo & Caju & Melancia \\
Erva-cidreira-de-folha & Cana-de-açúcar & Milho xavante \\
Feijão & Feijão xavante & \\
Melancia & Feijão-guandu & \\
Milho xavante & Jatobá & \\
Milho & Mandioca brava & \\
Mamão & Mamão & \\
& Melancia & \\
& Milho & \\
& Milho xavante & \\
& Urucum & \\
& &
\end{tabular}

Para Sahlins ${ }^{[18]}$ em sociedades de agricultores, maior tempo é dedicado para as atividades produtivas em comparação com sociedades que têm sua subsistência baseada na caça e coleta. Silva ${ }^{[19]}$ chamou atenção na década de 80, para o fato de que os xavantes estavam se tornando agricultores e este evento poderia fazer com que eles gastassem mais tempo com esta atividade, e menos para a vida social. Entretanto, com o fim da mobilidade espacial e o incremento da agricultura, o tempo 
dedicado à vida social parece não ter sido alterado a priori, pois todas as famílias estão sempre em contato e mesmo quando há rituais nas aldeias próximas (Pimentel Barbosa e Etenhitípá), os membros de Wede'rã participam. Isto indica que o tempo dedicado à agricultura não os impede de participarem de festas e rituais. Este fato também foi comprovado pela realização de jogos de futebol entre as aldeias do território, observado em 2008. A fixação das aldeias parece ter contribuído para o aumento da convivência entre famílias, com realização de novas atividades sociais, como tais jogos.

Com relação aos quintais, estes se possuem alta diversidade de espécies, tanto nativas do cerrado, quanto exóticas. Este incremento também é atribuído à ação do projeto da ONG Nossa Tribo. Assim, o uso dos quintais pode ser considerado uma interferência positiva, sendo uma possibilidade de fonte complementar de alimentos, do ponto de vista nutricional. Os indígenas consideram que estas áreas não são boas para os principais cultivos, como milho e feijão. As frutíferas não exigem muitos cuidados e tratos culturais e a introdução de nativas, adaptadas às condições locais, pode diversificar a alimentação ao longo do ano. tornaram importantes para produção agrícola e

Tabela 2. Espécies cultivadas nos quintais da aldeia Wede' rã entre 2005 e 2007.

\begin{tabular}{|c|c|c|c|c|c|c|}
\hline Casa 1 & Casa 2 & Casa 3 & Casa 4 & Casa 5 & Casa 6 & Casa 7 \\
\hline Abacaxi & Abacaxi & Abacaxi & Abacaxi & Abóbora & Abacaxi & Abacaxi \\
\hline Abóbora & Abóbora & Abóbora & Abóbora & Abare'ture & Abare'ture & Abóbora \\
\hline Caju & Abare'ture & Abare'ture & Abare'ture & Laranja & Abóbora sp.1 & Abare'ture \\
\hline Coco & Algodão & $\begin{array}{l}\text { Algodão } \\
\text { xavante }\end{array}$ & Baru & Melancia & Abóbora sp. 2 & $\begin{array}{l}\text { Algodão } \\
\text { xavante }\end{array}$ \\
\hline Jatobá & Baru & Caju & Babaçu & $\begin{array}{l}\text { Mandioca } \\
\text { brava }\end{array}$ & Amendoim & Caju \\
\hline Laranja & Banana & Coco & Caju & Tomonti & $\begin{array}{l}\text { Algodão } \\
\text { xavante }\end{array}$ & Laranja \\
\hline $\begin{array}{l}\text { Mandioca } \\
\text { brava }\end{array}$ & $\begin{array}{l}\text { Batata-doce } \\
\text { Buriti }\end{array}$ & Erva-cidreira & Cará & Zoroin'ró & Baru & $\begin{array}{l}\text { Mandioca } \\
\text { doce }\end{array}$ \\
\hline $\begin{array}{l}\text { Mandioca } \\
\text { doce }\end{array}$ & Caju & Jatobá & Erva-cidreira & & Caju & $\begin{array}{l}\text { Mandioca } \\
\text { brava }\end{array}$ \\
\hline Mamão & Cana & Laranja & Jatobá & & Cará & Manga \\
\hline Manga & Cará & Macaúba & Laranja & & Coco & Macaúba \\
\hline Macaúba & Cabaça & $\begin{array}{l}\text { Mandioca } \\
\text { brava }\end{array}$ & Limão & & Erva-cidreira & Melancia \\
\hline Melancia & Coco & Melancia & Macaúba & & $\begin{array}{l}\text { Feijão } \\
\text { xavante }\end{array}$ & Pequi \\
\hline Milho xavante & Erva-cidreira & Pequi & Manga & & Feijão & \\
\hline Pequi & Gengibre & Urucum & $\begin{array}{l}\text { Mandioca } \\
\text { brava }\end{array}$ & & Laranja & \\
\hline Urucum & Laranja & & Melancia & & Macaúba & \\
\hline \multirow[t]{10}{*}{ Zoroin 'ró } & Limão & & Pequi & & Manga & \\
\hline & Mamão & & Timbó & & $\begin{array}{l}\text { Mandioca } \\
\text { brava }\end{array}$ & \\
\hline & Macaúba & & & & Melancia & \\
\hline & Manga & & & & $\begin{array}{l}\text { Milho } \\
\text { xavante }\end{array}$ & \\
\hline & Mandioca doce & & & & Mooni'häiré & \\
\hline & Mandioca brava & & & & Zoroin'ró & \\
\hline & Melancia & & & & & \\
\hline & Medicinal* $^{*}$ & & & & & \\
\hline & Pequi & & & & & \\
\hline & Tomonti & & & & & \\
\hline
\end{tabular}




\section{Compra de alimentos}

Se a produção do arroz pode ser considerada o principal fator de alteração alimentar dos xavantes, uma nova modalidade de acesso aos alimentos que tem contribuído para um desequilíbrio, é a compra de produtos industrializados, particularmente aqueles ricos em carboidratos. A aquisição destes é proporcionada por aposentadorias de alguns membros da aldeia e pelo salário dos professores da escola ali existente. Normalmente as compras são realizadas pelos homens, que vão com mais frequiência à cidade.

Em cada casa, foram obtidas informações sobre os itens comprados para alimentação. Nestas entrevistas foram anotados apenas os itens informados pelos entrevistados, tentando não provocar interferência do pesquisador, deixando o informante livre para informar os itens que compõem sua compra. Há que se reconhecer que também neste caso, pode haver seleção por parte deste, dos itens que prefere relatar.

Estes dados estão listados na Tabela 3 e representam informações entre os anos de 2005 e 2007. Nesta Tabela não constam informações referentes a casa 7, devido a esta ter sido construída em 2008, com a constituição de uma nova família.

Tabela 3. Itens comprados pelos moradores da aldeia Wedé rã.

\begin{tabular}{llllll}
\hline Casa 1 & Casa 2 & Casa 3 & Casa 4 & Casa 5 & Casa 6 \\
\hline Açúcar & Açúcar & Açúcar & Açúcar & Açúcar & Açúcar \\
Alho & Alho & Alho & Alho & Banana & Alho \\
Arroz* & Arroz* & Arroz* & Arroz* & Café & Arroz \\
Banana & Banana & Balinha & Feijão & Farinha & Café \\
Café & Café & Cebola & Limão & Feijão & Cebola \\
Carne bovina & Cebola & Feijão & Macarrão & Laranja & Extrato de tomate \\
Cebola & Feijão & Óleo & Melancia & Limão & Feijão \\
Extrato de tomate & Laranja & Sal & Óleo & Melancia & Frango \\
Farinha de trigo & Macarrão & & Pão & Óleo & Macarrão \\
Feijão & Melancia & & Sal & Sal & Óleo \\
Frango & Óleo & & & & Sal \\
Laranja & Pão & & & & \\
Macarrão & Pipoca & & & & \\
Melancia & Sal & & & & \\
Mexirica & & & & & \\
Óleo & & & & \\
Sal & & & & & \\
\hline
\end{tabular}

* Produto comprado após o término do Projeto de cultivo mecanizado de arroz.

Observa-se que em 2006 não havia a compra de arroz e com o fim do projeto de agricultura mecanizada, houve a compra deste produto, podendo indicar uma adesão a este alimento de forma mais duradoura. 
Interessante observar que a quantidade comprada não corresponde à maior parcela de alimentos consumida. Por outro lado, há que considerar que a comunidade não possui informações sobre valor nutricional dos alimentos, o que pode explicar o alto consumo de arroz, em substituição aos demais alimentos. Também não há trabalhos que esclareçam estas informações à comunidade.

\section{A alimentação escolar}

A escola existente na aldeia pertence à Secretaria de Educação do Município de Canarana/MT e recebe alimentos, que são preparados e distribuídos aos alunos. Estes estão listados na Tabela 4 e não variaram entre os dois anos de nosso estudo, conforme informação do órgão responsável. Há na escola aproximadamente 25 alunos que recebem os alimentos da merenda escolar.

Conforme pode ser observado a maioria dos itens alimentares constantes na merenda podem ser identificados com padrões da cultura não-índia e que, portanto, não levam em consideração hábitos culturais xavantes.

Tabela 4 - Itens da merenda escolar dos anos de 2006 e 2007.

\begin{tabular}{ll}
\hline Item & Quantidade* \\
\hline Açúcar & $5 \mathrm{~kg}$ \\
Arroz & $20 \mathrm{~kg}$ \\
Batata inglesa & $3 \mathrm{~kg}$ \\
Bolacha doce & $4 \mathrm{~kg}$ \\
Bolacha salgada & $3.2 \mathrm{~kg}$ \\
Carne de frango & $8 \mathrm{~kg}$ \\
Carne moída & $6 \mathrm{~kg}$ \\
Creme de milho & $4 \mathrm{~kg}$ \\
Extrato de tomate & $1 \mathrm{~kg}$ \\
Farinha de mandioca & $6 \mathrm{~kg}$ \\
Feijão & $5 \mathrm{~kg}$ \\
Leite em pó & $6 \mathrm{pct}$ \\
Macarrão com ovos & $6 \mathrm{~kg}$ \\
Óleo de soja & $4 \mathrm{latas}$ \\
Sal & $2 \mathrm{~kg}$ \\
Tempero (alho/sal) & $1 \mathrm{lata}$ \\
\hline *as quantidades referidas são entregues mensalmente \\
pela Prefeitura.
\end{tabular}

Foi construída uma cozinha próxima à escola, com fogão a gás e um forno, onde há o preparo das refeições distribuídas. $\mathrm{O}$ forno às vezes é usado pelos moradores para preparo de pães. A merenda é preparada por uma mulher da própria comunidade e as rotinas do preparo desta não foram acompanhadas.

Em Wederã a merenda constitui importante fonte alimentar e a prefeitura introduziu o consumo de leite, pois para o órgão responsável, este é um alimento importante para as crianças. Esta nova fonte de alimentos pode ser uma contribuição positiva, pois se torna importante fonte de cálcio e proteínas, e é destinada aos indivíduos de faixa etária em que as mudanças são mais perceptíveis. Adams et al ${ }^{[20]}$ identificaram entre populações ribeirinhas, que a merenda escolar constituía parte importante da alimentação das crianças.

\section{O consumo de alimentos}

As dificuldades para obter as informações relativas ao consumo alimentar das famílias se deramem função deste ser um trabalho que exige a permanência do pesquisador nas residências e da necessidade de ter um tradutor para as entrevistas. Além disso, as refeições do pesquisador eram preparadas à parte das refeições da comunidade.

Os dados deste trabalho são referentes às épocas do ano que coincidiram com a visita do pesquisador, não abordando a distribuição ao longo das estações. Estas informações estão listadas nas Tabelas 5, 6 e 7 . 
Tabela 5 - Consumo de alimentos - outubro/2005.

\begin{tabular}{llllll}
\hline Casa 1 & Casa 2 & Casa 3 & Casa 4 & Casa 5 & Casa 6 \\
\hline Arroz & Arroz & Arroz & Arroz & Arroz & Arroz \\
Feijão & & Pequi & Feijão & Feijão \\
Pequi & & & Peixe & Pequi \\
& & & & Carne bovina \\
& & & & Tomate \\
& & & & Repolho
\end{tabular}

Tabela 6 - Consumo de alimentos - outubro/2006.

\begin{tabular}{llllll}
\hline Casa 1 & Casa 2 & Casa 3 & Casa 4 & Casa 5 & Casa 6 \\
\hline Farinha & Arroz & Arroz & Sem inf. & Arroz & Sem inf. \\
Cervo & Cervo & Cervo & & Feijão & \\
& & & & Cervo & \\
\end{tabular}

Tabela 7 -Consumo de alimentos - janeiro/2008.

\begin{tabular}{llllll}
\hline Casa 1 & Casa 2 & Casa 3 & Casa 4 & Casa 5 & Casa 6 \\
\hline Arroz & Abóbora & Arroz & Arroz & Arroz & Arroz \\
Abóbora & Arroz & Feijão & Abóbora & Feijão & Abóbora \\
Feijão & Melancia & Melancia & & Melancia & \\
\hline
\end{tabular}

Os dados demonstram que, conforme já referido, o arroz se incorporou à dieta xavante, sendo base da alimentação e, por vezes, o único alimento consumido durante o dia.

Um fato interessante se refere ao consumo da carne de cervo, comum em todas as casas entrevistadas em 2006. Este fato devese à caça de um animal por um membro da comunidade e que dividiu a carne com toda a aldeia.

Nos itens comprados, verifica-se a predominância de produtos com alto valor em carboidratos e o que chama atenção é que em todas as casas há compra de feijão industrializado. Quando a ONG Nossa Tribo distribuiu sementes desta cultura, a comunidade não as plantou devido à preferência pela variedade tradicional, conforme depoimento, mesmo não possuindo quantidade suficiente desse alimento. Este é um aspecto interessante, os xavantes consomem qualquer tipo de feijão, mas só plantam a espécie tradicional. Observa-se também que há compras de frutas, pois são produtos muito apreciados na alimentação, principalmente a laranja.

A partir do momento que as famílias de Wede'rã passaram a ter fontes de renda, aumentaram o consumo de produtos industrializados, em detrimento dos tradicionais e nem sempre os produtos adquiridos são de alto valor nutritivo. Alterações semelhantes entre os xerentes foram relatadas por Farias ${ }^{[21]}$, em que a venda 
de artesanatos, proporcionava renda para a compra de alimentos industrializados, normalmente ricos em carboidratos. Tal fato também foi observado por Laraia e Da Matta ${ }^{[22]}$ entre os índios Gaviões e por Leite ${ }^{[14]}$ entre os wari, em que estas comunidades vendiam produtos em mercados regionais e com o dinheiro adquiriam produtos industrializados.

A introdução e o aumento no consumo de itens industrializados entre povos indígenas têm provocado sérios problemas de saúde, principalmente em crianças. De Lavor ${ }^{[23]}$ relatou entre os indígenas de Mato Grosso do Sul, a elevada prevalência de anemia, atingindo mais de $50 \%$ da população infantil em algumas aldeias. Este fato, segundo o autor, reflexo do processo de transição nutricional, em que predominam altas taxas de anemia e desnutrição entre crianças e obesidade entre adultos.

Por outro lado, de acordo com pesquisa relativa sobre as repercussões do Programa Bolsa Família na Segurança Alimentar e Nutricional ${ }^{[24]}$, o aumento do consumo de açúcares e carboidratos é uma tendência nacional. Segundo a autora do artigo, "tal situação expressa insegurança alimentar assim como desnutrição, fome, e outras doenças associadas à má alimentação e ao consumo de alimentos de qualidade duvidosa ou prejudicial à saúde".Políticas públicas de educação alimentar poderiam ser implementadas, incentivando um consumo de alimentos saudáveis e adequados cultural e ambientalmente. Entretanto, indaga a autora, como incentivar esse tipo de ação, sem assumir uma postura moralizante, baseada nas próprias concepções? Este questionamento também pode ser aplicado no contexto do presente trabalho.

Paralelamente ao consumo de novos alimentos, os xavantes ainda consomem alimentos tradicionais que eles mesmos produzem para o auto-consumo.

A farinha de mandioca é muito apreciada, além de importante na dieta, sendo produzidos dois tipos: a puba e farinha seca. Durante o trabalho de campo, observou-se apenas a produção de farinha seca, torrada em um tacho de ferro a céu aberto. Durante seu preparo, todos têm oportunidade de consumir o produto e no término do preparo, a farinha é distribuída a todos. Há também o preparo de um tipo de beiju com mandioca branca. Os homens mais idosos da aldeia relataram que antes do contato com não-índios, este alimento era feito com uma espécie de mandioca vermelha (Pahu'pré), preparado em panelas de barro, e consumido com carne de caça. Também era utilizado para a elaboração de mingaus preparados com abóbora e misturados com milho e feijão. Atualmente não há mais consumo da mandioca vermelha devido à perda desta planta, existindo apenas o consumo de mandioca branca (brava e doce). Foi observado o consumo de mingau de abóbora e informaram preparar o feijão xavante junto com arroz, sendo estes cozidos juntos, pois este feijão possui tempo de cozimento próximo ao do arroz. Também pôde ser observado o consumo de milho e carás assados nas brasas das fogueiras das cozinhas.

A prática de troca de alimentos é comum entre esses indígenas. Uma mulher relatou que em certa época, todas as casas haviam colhido muitas melancias. Mesmo 
havendo esta fruta em todas, estas eram distribuídas a todos, e rindo contou que quando chegavam às casas com estes frutos, e alguém falava que já possuía, eles respondiam que aquele era "especial" e era "muito bom".

A comida é preparada pelas mulheres e a cozinha é separada das casas. O cozimento é feito em um tipo de fogueira, feita com pedras onde são apoiadas as panelas e a fonte de energia para o cozimento é constituída por lenha coletada pelas mulheres.

Pela manhã, em torno de 8:00 a 9:00 horas, as mulheres começam a preparar as refeições e se vê a fumaça saindo pelo telhado das cozinhas. Estas são construídas de forma semelhante às casas, com palha e madeira e no centro se encontra a fogueira, utilizada para preparo das refeições. Estas são realizadas por volta de 10:00 horas da manhã e antes da realização do $w a r \tilde{a}^{8}$. Quando os homens saem para caçar, chegando com a carne, logo esta é preparada e consumida, normalmente cozida ou quando em grande quantidade, assada.

$\mathrm{Na}$ aldeia Wede'rã cria-se somente frangos, e a fonte de proteína na alimentação tem sua origem praticamente só na caça, conforme referido anteriormente. Vale referir que eles manifestaram interesse em aumentar a criação de frangos e o seu consumo. Entretanto, como a caça faz parte da vida espiritual xavante e é valorizada na sociedade, talvez esta mudança não ocorra em curto prazo.

${ }^{8}$ Reunião dos homens, que é realizada todos os dias, no fim da tarde.

\section{Conclusões}

Os projetos inseridos na comunidade xavante provocaram alterações na alimentação, com reflexos na sua organização social.

Com o incremento de produtos da agricultura, principalmente o arroz, o equilíbrio alimentar não é alcançado, considerando-se a homogeneização e redução da variabilidade de itens na dieta. Como os cultivos ocorrem nas épocas chuvosas, não há disponibilidade de produtos ao longo do ano todo e não se aproveita a sazonalidade de produtos do cerrado, devido à redução da coleta. Além disso, a delimitação do território e o desmatamento do entorno, tem aumentado a dificuldade da caça, a principal fonte de proteína.

Todos esses fatores aliados à atração dos produtos industrializados comprados na cidade e ainda, à composição das refeições distribuídas pelo programa de alimentação escolar dão indicativos de que os problemas nutricionais identificados poderão se agravar se políticas para reverter este quadro não forem adotadas.

Há necessidade de um rigor maior na aprovação de projetos destinados à população indígena, pois aqueles que não consideram os valores sócio-culturais nas práticas de subsistência, acabam por interferir nas relações entre indivíduos e destes com a natureza, além de poderem gerar ou agravar os problemas de segurança alimentar e nutricional. 


\section{Agradecimentos}

À aldeia xavante Wedérã, pela oportunidade dada à realização deste trabalho e aprendizado.

\section{Referências bibliográficas}

[1] Maybury-Lewis, D. A sociedade xavante. Rio de Janeiro: Editora Francisco Alves; 1984.

[2] Silva, AL. Povos indígenas do Brasil. Instituto Socioambiental; 1992 [citado em: 2007 jan 23]; Disponível em: www.socioambiental.org.br

[3] Giaccaria, B; Heide, A. Xavante: povo autêntico - pesquisa histórico etnográfica. São Paulo; Editorial Dom Bosco; 1972.

[4] Gauditano, R. Raízes do povo xavante: tradição e rituais. Vários patrocinadores. São Paulo; 2003.

[5] Barbosa, HB; Craveiro, S (Org.). Na trilha da cidadania: iniciativas para a promoção dos direitos das comunidades indígenas. São Paulo: Programa Gestão Pública e Cidadania; 2004.

[6] Relatório parcial do Projeto Nutrição infantil para os xavantes - ONG Nossa Tribo, 2007.

[7] Gugelmin, SA; Santos, RV. Ecologia humana e antropometria nutricional de adultos Xavánte, Mato Grosso, Brasil. Cadernos de Saúde Pública; 2001; 17, 2: 312-322.

[8] Vieira Filho, JPB. Problemas da aculturação alimentar dos Xavantes e Bororo. Revista de Antropologia; 1981; 24:37-40.
[9] Orellana, JDY; Coimbra Jr., CEA; Lourenço, AEP; Santos, RV. Estado nutricional e anemia em crianças Suruí, Amazônia, Brasil. Jornal de Pediatria; 2006; 82; 5:383-388.

[10] Instituto socioambiental. Enciclopédia dos povos indígenas. Instituto socioambiental; 2000.

[11] Viertler, RB. Ecologia cultural: uma antropologia da mudança. São Paulo: Ática, Série Princípios; 1988.

[12] Stearman, AM. Cambio social, cacería y conservación en pueblos indígenas. Puntos de conflicto y caminos hacia la resolución. In: Fang, TG; Montenegro, OL; Bodmer, RE (Ed.). Manejo y conservación de fauna silvestre en America Latina. La Paz: Instituto de Ecología; 1999.

[13] Setz, EZF. Estratégia de forrageio em populações indígenas de florestas neotropicais. Belém: Museu Paraense Emílio Goeldi, Coleção Eduardo Galvão; 1989. p. 77-94.

[14] Leite, MS. Transformação e persistência: antropologia da alimentação e nutrição em uma sociedade indígena amazônica. Rio de Janeiro: Fiocruz; 2007.

[15] Pinto, JG; Garavello, ME de PE. Transformação (agri)cultural ou etnossustentabilidade: relato de uma aldeia Bororo. Agroecologia e Desenvolvimento Rural Sustentável; 2002; 3; 2: 54-60.

[16] Sahlins, M. Sociedades tribais. Rio de Janeiro: Zahar Editores; 1974. 
[17] Leite, DM. Produção do grupo. Tópicos em psicologia social. São Paulo: Editora da Universidade de São Paulo; 1973.

[18] Sahlins, M. A primeira sociedade da afluência. In: Carvalho, EA (Org). Antropologia econômica. São Paulo: Livraria Editora Ciências Humanas; 1978.

[19] Silva, AL. Xavante: casa - aldeia - chão - terra - vida. In: Caiuby, SN (Org). Habitações indígenas. São Paulo: Editora da Universidade de São Paulo; 1983.

[20] Adams, C; Murrieta, RSS; Sanches, RA. Agricultura e alimentação em populações ribeirinhas das várzeas do Amazonas: novas perspectivas. Ambiente \& Sociedade; 2005; 8; 1: 65-86.

[21] Farias, AJTP. Fluxos Sociais Xerente: Organização Social e Dinâmica das Relações Entre Aldeias. [Dissertação]. São Paulo: Faculdade de Filosofia, Letras e Ciências Humanas; 1994. 196p.

[22] Laraia, RB; da Matta, RA. Índios e castanheiros. São Paulo: Difusão européia do livro, Coleção corpo e alma do Brasil; 1967.

[23] De Lavor, A. Saúde na fronteira oeste: panorama tão rico quanto vulnerável. Radis: comunicação em saúde; 2008; 75: 8-13.

[24] Mielniczuk, VB. Você tem fome de quê? Educação alimentar em foco. Democracia viva; 2008; 39; 53-57. 